Article

\title{
Lean VOC-Air Mixtures Catalytic Treatment: Cost-Benefit Analysis of Competing Technologies
}

\author{
Gabriele Baldissone *, Micaela Demichela and Davide Fissore \\ Dipartimento di Scienza Applicata e Tecnologia, Politecnico di Torino, Corso Duca degli Abruzzi 24, \\ 10129 Torino, Italy; micaela.demichela@polito.it (M.D.); davide.fissore@polito.it (D.F.) \\ * Correspondence: gabriele.baldissone@polito.it; Tel.: +39-011-090-4629
}

Received: 4 May 2017; Accepted: 18 June 2017; Published: 25 June 2017

\begin{abstract}
Various processing routes are available for the treatment of lean VOC-air mixtures, and a cost-benefit analysis is the tool we propose to identify the most suitable technology. Two systems have been compared in this paper, namely a "traditional" plant, with a catalytic fixed-bed reactor with a heat exchanger for heat recovery purposes, and a "non-traditional" plant, with a catalytic reverse-flow reactor, where regenerative heat recovery may be achieved thanks to the periodical reversal of the flow direction. To be useful for decisions-making, the cost-benefit analysis must be coupled to the reliability, or availability, analysis of the plant. Integrated Dynamic Decision Analysis is used for this purpose as it allows obtaining the full set of possible sequences of events that could result in plant unavailability, and, for each of them, the probability of occurrence is calculated. Benefits are thus expressed in terms of out-of-services times, that have to be minimized, while the costs are expressed in terms of extra-cost for maintenance activities and recovery actions. These variable costs must be considered together with the capital (fixed) cost required for building the plant. Results evidenced the pros and cons of the two plants. The "traditional" plant ensures a higher continuity of services, but also higher operational costs. The reverse-flow reactor-based plant exhibits lower operational costs, but a higher number of protection levels are needed to obtain a similar level of out-of-service. The quantification of risks and benefits allows the stakeholders to deal with a complete picture of the behavior of the plants, fostering a more effective decision-making process. With reference to the case under study and the relevant operational conditions, the regenerative system was demonstrated to be more suitable to treat lean mixtures: in terms of time losses following potential failures the two technologies are comparable (Fixed bed plant: $0.35 \mathrm{~h}$ /year and Reverse flow plant: $0.56 \mathrm{~h} /$ year), while in terms of operational costs, despite its higher complexity, the regenerative system shows lower costs $(1200 € /$ year).
\end{abstract}

Keywords: cost-benefit analysis; VOC treatment; lean mixtures; reverse-flow reactor; Integrated Dynamic Decision Analysis

\section{Introduction}

Different technologies are available for the treatment of gaseous streams containing VOCs (Volatile Organic Compounds), namely catalytic or homogeneous combustion, absorption, adsorption, etc. The goal is either to recover the VOCs, or to destroy them, thus avoiding, in both cases, their emission into the atmosphere.

The treatment of "lean" streams, where the concentration of the VOCs is particularly low (e.g., lower than $1 \%, v / v$ ), is a particularly challenging case study as the low concentration makes the VOC recovery technically and economically impractical. In this case, the catalytic combustion stands out as the reference technology as it allows fulfilling the constraints on the characteristics of the product released into the atmosphere [1]. Thus, in case of lean streams to be treated two competitive 
technologies can be regarded as effective: a catalytic fixed-bed reactor with a heat exchanger for heat recovery purposes, and an intensified plant, with a catalytic reverse-flow reactor, where regenerative heat recovery is achieved through the periodical reversal of the flow direction.

In fact, the temperature at which it is required to carry out the catalytic combustion ranges (in most cases) from $200{ }^{\circ} \mathrm{C}$ to $500{ }^{\circ} \mathrm{C}$, depending on the characteristics of the catalyst used and on the chemical compounds that have to be removed, while the temperature of the gaseous stream to be treated can be significantly lower, in some cases close to room temperature. This poses the problem of energy recovery: a large amount of energy is required to pre-heat the feed to the reaction temperature, and a fraction of this energy can be recovered from the treated gas to pre-heat the feed. In any case, a certain amount of energy has to be supplied, as the efficiency of this approach is usually not higher than about $70 \%$ [2].

In this framework, a particularly effective technology is represented by the reverse-flow reactor, firstly proposed by Cottrell [3]. The operating principle of the reverse-flow reactor is particularly simple: at first, the reactor is pre-heated to the target temperature and, then, the gaseous stream is fed to the reactor. As a consequence, the gas is heated by the solid, thus reaching the reaction temperature (and cooling the solid material close to the entrance of the reactor), and, then, it heats the solid before leaving the reactor. After a certain time, which has to be carefully selected, the flow direction is reversed and, now, the hot gas, before leaving the reactor, heats the solid that has been cooled in the previous stage of reactor operation. In this way, a regenerative heat recovery is achieved in the reactor, where the ending sections act as two heat exchangers, storing the heat from the hot gas after combustion, and, then, pre-heating the cold gas fed to the reactor. As the ending sections of the reactor acts as heat exchangers, the catalyst here can be replaced by inert material, thus reducing catalyst cost [4]. This system was widely investigated in the past, both from the theoretical and the experimental points of view [5-9], evidencing the possibility of operating in presence of streams with composition and concentration variable in time $[10,11]$, and also with a monolith type catalyst, to reduce the pressure drop in the system [12]. All these studies evidenced the key role of the switching time: a high switching frequency is required to enhance the "heat trap" effect due to the periodical flow reversal and, thus, to get autothermal combustion when feeding a very lean gas. Unfortunately, after each flow reversal a certain amount of gas and VOCs remaining in the entrance of the reactor is released into the atmosphere (wash-out phenomenon), and this is particularly relevant in case of high switching frequencies. Although some alternative reactor configurations have been proposed to cope with this problem (see, among the others, Kolios et al. [13]; Luzi et al. [14]), the use of an electrical heater in the central part of the system appears to be a particularly simple and effective solution to treat a low concentration stream, avoiding too high switching frequencies [2].

The above described defines the major aim of this paper: defining an optimized approach to support the decision-making process among possible plant and process alternatives, based on the risk associated with the different competing options. In particular, among the possible tools available for the risk-based decision making, the Integrated Dynamic Decision Analysis (IDDA) has been chosen, since it was demonstrated in several papers [15-18] to be more effective in assessing the risks, giving a more complete representation of the system behavior and also in facilitating the knowledge transfer. The risk considered for comparison purposes has been expressed in terms of costs, to be in line with the typical decisional process of the stakeholders and decision makers, thus adopting a cost-benefit analysis (CBA) approach.

As discussed in Saarikoski et al. [19], the cost-benefit analysis (CBA) is an economic evaluation method for comparing the costs and benefits of different projects or policy options [20]. CBA aims to value all impacts of project alternatives in monetary units, possibly discounted to a specified year, making it possible to screen or rank alternatives by a single monetary measure, often the net present value (NPV). The basic steps of CBA, according to Boardman et al. [21], can be summarized as follows:

1. The definition of the project options to be evaluated: in the present case, the two competing technologies for VOC treatment above described; 
2. The decision on which costs and benefits are accounted for and the selection of the measurement method to evaluate all the costs and benefits: as described later on, the costs here used to compare the two alternatives are the operational costs, the variable costs to be taken into account with the investment costs for the equipment, and the time losses in case of malfunction;

3. The estimation of costs and benefits over a relevant time period and their conversion into a common currency, discounted into present value: dealing with operational costs, the reference period has been assessed over one year of operation.

4. Drawing the recommendations based on the costs and benefits and the sensitivity analysis, when available: the decision making was in this case supported not only by the costs figures, but also on the logical-probabilistic model of the two systems, jointly analyzed with the phenomenological model of the process through the Integrated Dynamic Decisional Analysis methodology.

The CBA is used in several field as: in the waste management [22], in the medical resource allocation [23], and in the energy management [24]. A sensitivity analysis was not performed, since all the input parameters required for plant design have been selected equal to the optimal values, according to the available know-how on these technologies, as it will be discussed in the following.

The Integrated Dynamic Decisional Analysis (IDDA) was firstly proposed by Galvagni $[25,26]$ and, then, it was applied to different case studies, e.g., tank overflowing [15,16], risk-based design of an allyl-chloride production plant [27], analysis and optimization of procedures for LPG tanks maintenance and testing [28]. The IDDA methodology is based on the combined use of a logical-probabilistic model of the system under analysis and its phenomenological model. The logical-probabilistic model allows identifying all potential sequences of events the system can undergo and their probability of occurrence, and it can be coupled to a phenomenological model, i.e., a mathematical description of the process plant behavior both in case of normal condition and in case of equipment faults. The phenomenological model is used to evaluate the consequences for each sequence of events, and the overall risk value. The joint modelling, that still constitutes a novelty in the process domain of application, allows a risk-based decision making to be performed, as discussed in Piccinini \& Demichela [15] and in Demichela \& Camuncoli [16].

This paper is structured as follows: Chapter 2 is dedicated to the description of the two competing technologies under study, with the logical and probabilistic model and the phenomenological one developed to simulate and foreseen their behavior in case of correct functioning and in case of failures. Chapter 3 shows the results of the analysis, with a comparison of the performances of two plant alternatives in terms of costs and benefits. In the end, some technical and methodological conclusions are drawn.

\section{Case Study}

The case study considered in this paper is the treatment of $5000 \mathrm{Nm}^{3} / \mathrm{h}$ of a gaseous stream obtained from a polymerization plant. The stream is composed of ethylene glycol, $0.2 \% v / v$, and nitrogen: oxygen has thus to be added to this gas as the VOC is removed through catalytic combustion. The gas temperature is $230^{\circ} \mathrm{C}$, while the pressure is 1.17 bar. After VOC removal (the target concentration of VOC in the product stream has to be lower than $50 \mathrm{ppm}$ ), the gaseous stream is recycled to the polymerization plant: as the presence of oxygen is highly undesired in the recycled stream, great care has to be paid when adding the oxygen in the feed, and when carrying out the catalytic combustion, in such a way that (almost) no unreacted oxygen is present in the product (the constraint considered in this study is that the oxygen concentration in the treated has to be lower than $0.01 \%$ ).

The performance of two plants has been compared in this paper. The first is based on a traditional fixed-bed reactor, while the second comprises a reverse-flow reactor. In both cases the VOC is removed through catalytic combustion. In the fixed-bed reactor a commercial catalyst based on Platinum $(0.15 w / w)$ and Palladium $(0.15 \% w / w)$ over alumina (type K-02120 by Heraeus, Hanau, Germany) has been considered. The catalyst is supplied as pellets, with a diameter ranging from 2 to $4 \mathrm{~mm}$, with a BET surface area of $115 \mathrm{~m}^{2} / \mathrm{g}$. The GHSV (Gas Hourly Space Velocity) suggested by the catalyst supplier is $10,000 \mathrm{~h}^{-1}$, with an operating temperature of $350{ }^{\circ} \mathrm{C}$. In the second reactor a metal oxides based 
commercial catalyst (EnviCat ${ }_{\circledast}$ VOC-1544 by Sud-Chemie, Munich, Germany), composed of cooper $(3.34 \% w / w)$ and manganese $(5.44 \% w / w)$ oxides over alumina, has been considered. The catalyst is supplied as pellets, with a diameter ranging from 4 to $6 \mathrm{~mm}$, with a BET surface area of $73 \mathrm{~m}^{2} / \mathrm{g}$. The GHSV (Gas Hourly Space Velocity) suggested by the catalyst supplier is $15,000 \mathrm{~h}^{-1}$, with an operating temperature of $430{ }^{\circ} \mathrm{C}$. The rational for the choice of two different catalysts is the fact that in the reverse-flow reactor it is much easier to get higher temperatures (as it is just required to increase the switching frequency, without introducing additional heat) with respect to the fixed-bed reactor and, thus, the use of the metal oxides based catalyst, whose operating temperature is lower, allows reducing the catalyst cost.

For the reactor sizing, more conservative values of GHSV, with respect to those suggested by the catalyst suppliers, have been considered, namely $5000 \mathrm{~h}^{-1}$ for the Pt-Pd based catalyst and $10,000 \mathrm{~h}^{-1}$ for the $\mathrm{Cu}-\mathrm{Mn}$ oxides based catalyst. Moreover, for the reverse-flow reactor based plant the use of inert particles, alumina spheres with the same diameter of the catalyst particles, has been considered to increase the heat capacity of the system: the same amount of inert and of catalyst has been assumed, and the reactor has been divided into three sections, namely a first inert layer, the catalyst layer and the second inert layer. By this way in both cases the reactor has the same size, namely $1.5 \mathrm{~m}$ diameter, and $0.6 \mathrm{~m}$ length.

A simplified sketch of the fixed-bed based plant is shown in Figure 1. Beside the catalytic reactor, the plant is composed of the following pieces of equipment:

- a gas blower (B01), used to feed the plant;

- an oxygen feeding line, used to feed the required amount of oxygen in the system, on the basis of the measurement of the oxygen concentration in the gas leaving the plant;

- a filter (F01), used to stop particles suspended in the gaseous stream;

- a heat exchanger (H01), used to pre-heat the feed using the hot gas leaving the reactor;

- a heater (H02), used to heat the feed to the combustion temperature,

- a reactor (R01), used to conduct the combustion reaction.

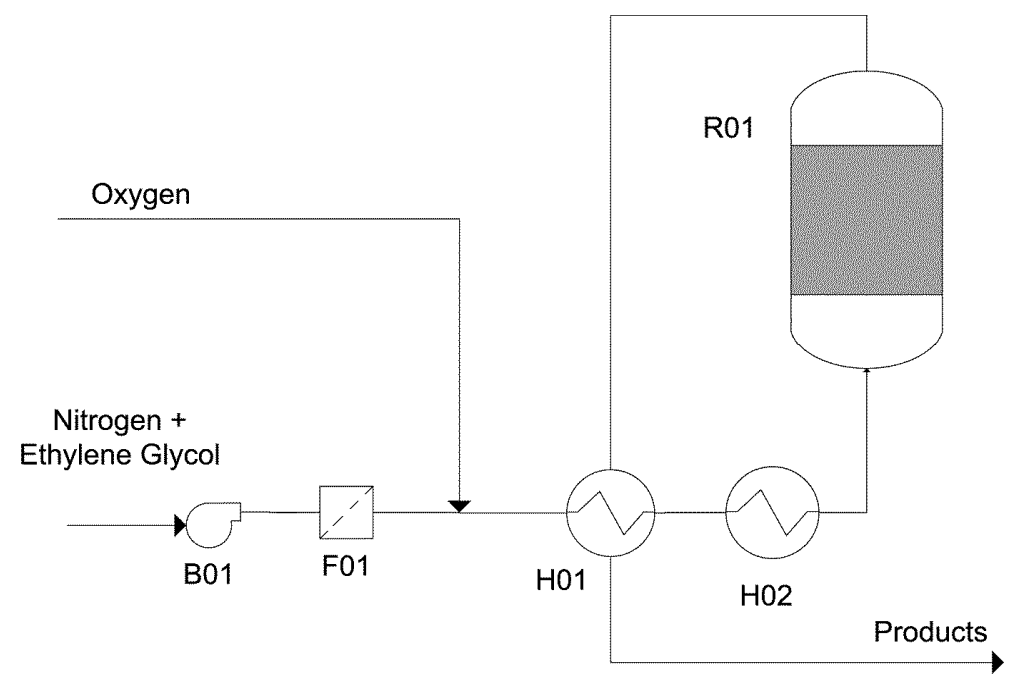

Figure 1. Sketch of the plant for the treatment of air-VOC mixtures in a steady-state fixed-bed reactor.

With respect to the alarms and control/protection systems used in this plant, the following can be listed:

- High concentration alarm in the feed line, indicating when the VOC concentration of the feed exceeds a certain threshold ( $0.5 \%$ in this case), as the high concentration of the feed would be responsible for a too high temperature in the reactor, with a consequent catalyst deactivation; 
- High temperature alarm after the blower: it alerts the operator when the temperature is higher than a certain threshold $\left(270{ }^{\circ} \mathrm{C}\right.$ in this case) to prevent filter damages;

- Differential pressure alarm in the filter, indicating filter blocking;

- High/Low temperature alarms in the gas line exiting H01: if the temperature is higher than a certain threshold $\left(450{ }^{\circ} \mathrm{C}\right.$ in this case), then catalyst overheating and damages can occur, while if the temperature is lower than a certain threshold $\left(300^{\circ} \mathrm{C}\right.$ in this case), then it would not be possible to reach the temperature required to get a full VOC removal in the reactor;

- High temperature alarm in the gas line exiting H02: it alerts the operator if the temperature is higher than a certain threshold $\left(450^{\circ} \mathrm{C}\right.$ in this case) and, thus, catalyst damages can occur. Due to the importance of this alarm, temperature is measured by a series of sensors operating logic on voting (2:3);

- High temperature alarms in the reactor: when the temperature is higher than a first threshold $\left(400{ }^{\circ} \mathrm{C}\right.$ in this case) the operator is alerted and, if the temperature continues increasing, after a second threshold $\left(450{ }^{\circ} \mathrm{C}\right)$ a protection system is activated, causing the shut-down on the system;

- High oxygen concentration alarm in the product stream, indicating that too much oxygen is present in the product stream and, thus, it cannot be recycled to the polymerization plant;

- High VOC concentration alarm in the product stream, indicating that the VOC concentration is too high and, thus, that the catalytic reactor is not working properly.

A simplified sketch of the reverse-flow reactor based plant is shown in Figure 2. Besides some elements similar to the fixed-bed based plant, namely the blower B01, the filter F01, the reactor R01, and the oxygen feeding line, the plant comprises the following pieces of equipment:

- a heat exchanger (H01), used in the start-up phase and for control purposes (according to the design of Fissore et al. [9]);

- a set of valves (V01, V02, V03, V04) used to periodically reverse the gas flow direction: when valves V01 and V04 are open, and V02 and V03 are closed, the gas flows from the top to the bottom of the reactor, while the opposite occurs when valves V01 and V04 are closed and V02 and V03 are open. Valve V05 is usually closed, and used only for control purposes.

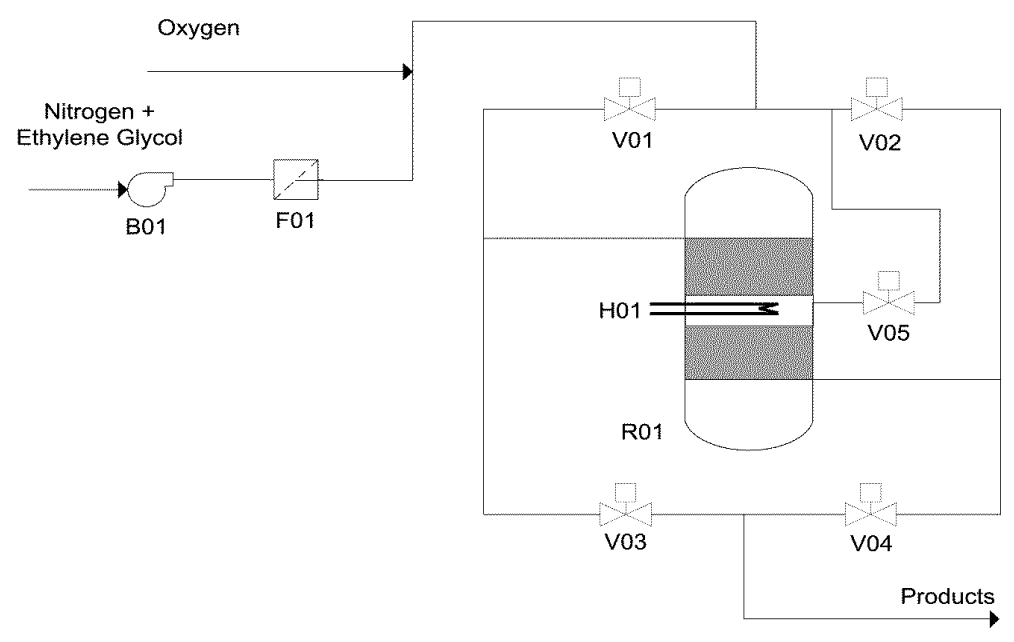

Figure 2. Sketch of the plant for the treatment of air-VOC mixtures in a reverse-flow reactor.

With respect to the alarms and control/protection systems, for the feeding/product lines, as well as for the gas blower and the filter, the same alarms previously described for the fixed-bed reactor based plant are used also in this case. The alarms and the control/protection systems used for the reactor are different, according to the system proposed by Barresi et al. [2] and based on the 
temperature measurement at the interface between the inert and the catalyst sections, where the reactor temperature is higher. In case this temperature is decreasing from the set-point value, when it reaches $410^{\circ} \mathrm{C}$, the heating capacity of $\mathrm{H} 01$ is set at the maximum value, the switching time is reduced and an alarm is activated. If the temperature continues decreasing, when it reaches the value of $390{ }^{\circ} \mathrm{C}$ a second alarm is activated and the shut-down of the reactor occurs. In case the temperature of the reactor increases, when it overtakes $500{ }^{\circ} \mathrm{C}$ a first protections system acts turning off the heater and increasing the switching time, and an alarm is activated. In case the temperature continues increasing, when it reaches the value of $530{ }^{\circ} \mathrm{C}$ another protection system is activated to protect the catalyst from the thermal degradation: in this case, the cold gas is feed directly in the middle of the reactor (opening the valve V05, and closing valves V01 and V02), and an alarm is activated.

\section{Materials and Methods}

\subsection{Integrated Dynamic Decisional Analysis}

\subsubsection{Logical Model}

The logical-probabilistic model is built starting from the process plant functional analysis, since it allows identifying and describing the events that could occur in the plant. Each event is included in the input model through a list of questions or affirmations, each of them characterized by the probability of occurrence for each level outcome, and, if available, by an uncertainty ratio, representing the distribution of the probability. Then a network is built indicating the subsequent level to be visited depending on the level outcome.

Figure 3 shows the structure of the logical-probabilistic analysis, declined for the sensing element AE01 described at level 10, characterized by a probability of failure of 0.062 . The numbers that follow represent the levels to be visited in case of correct functioning and in case of failure of the component analyzed: in this case the level 11 in case of positive outcome and level 15 in case of failure.

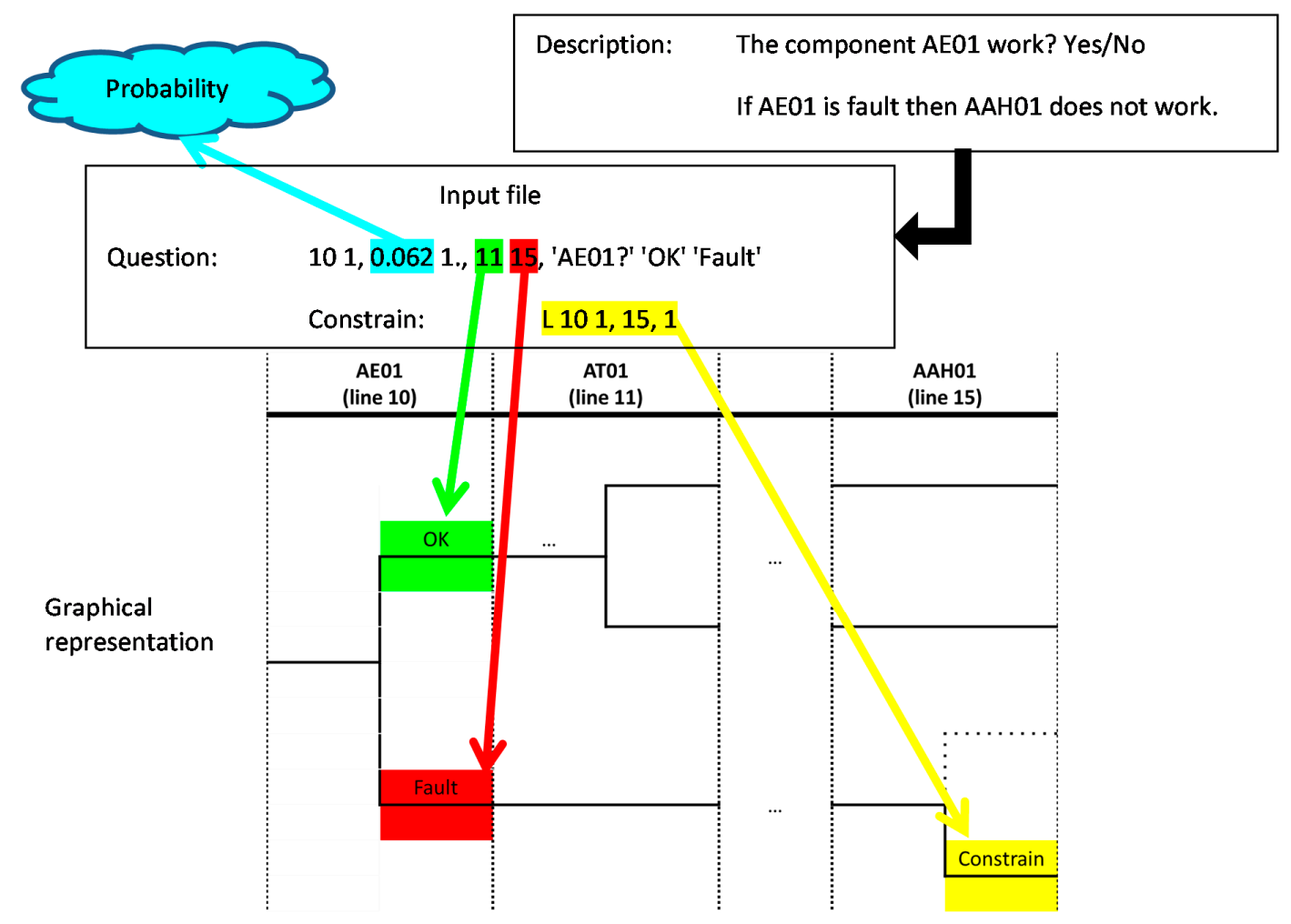

Figure 3. Graphical representation of the logical analyses structure. 
When needed, each level is accompanied by a row defining a logical and probabilistic constraints, in order to take into account how an event can influence the subsequent events. In the example of Figure 3, in case of negative outcome of level $10(101)$, the constraint forces the subsequent level to be visited (15) to the negative outcome also (1). This meaning that in case of failure of the sensing element, not only the control loop will fail, but also the alarm loop that depends on AE01.

The logical-probabilistic model is then built with IDDA 2.0 software (Software Oriented System Engineering S.r.l., Milan, Italy), elaborating all the possible sequences of events in the plant.

For both alternative process plants, the logical-probabilistic models were developed in the same way, by the systematic analysis of the equipment failure effects on the plant and of the protective devices and alarms effectiveness. The events occurrence probability was obtained by literature [29] and, where known, from the plant management. For an unbiased comparison of the two plants, the failure probability for similar pieces of equipment was considered to be the same.

For the fixed bed plant 3,901,910 sequences were generated and, with a cuff-off value of $10^{-16}$ a residual probability of $7.5 \times 10^{-11}$ was obtained. The cut-off value is a probability threshold: the sequences with probabilities lower than the cut-off value are neglected and the sum of the probabilities of the neglected sequences gives the residual probability.

For the reverse-flow plant analysis a cut-off value of $10^{-12}$ was used and 5,336,624 sequences of events were obtained, with a residual probability of $2.9 \times 10^{-6}$.

The cut-off value is obtained through an optimization on the residual probability value, to be minimized against the number of sequences to be included in the calculation with respect to the available computational resources.

Among all the possible consequences, the more critical events from the point of view of the process (Top Events) were selected, namely the discharge with an excess of VOCs and the catalyst sintering. In Table 1 the occurrence probability for the Top Events is shown for the two plants analyzed. With respect to catalyst sintering, the logical-probabilistic analysis for the reverse flow plant did not identify any sequence resulting in a probability of occurrence higher than the cut-off value. The sequences with 3 or less equipment failures, or undesired outcomes, were extracted and elaborated jointly with the phenomenological model.

Table 1. Results of the logical-probabilistic model.

\begin{tabular}{ccccc}
\hline \multirow{2}{*}{ Top Event } & \multicolumn{2}{c}{ Fixed Bed Plant } & \multicolumn{2}{c}{ Reverse Flow Plant } \\
\cline { 2 - 5 } & $\begin{array}{c}\text { Sintering of } \\
\text { Catalyst }\end{array}$ & $\begin{array}{c}\text { Discharge with } \\
\text { Excess of VOCs }\end{array}$ & $\begin{array}{c}\text { Sintering of } \\
\text { Catalyst }\end{array}$ & $\begin{array}{c}\text { Discharge with } \\
\text { Excess of VOCs }\end{array}$ \\
\hline Number of sequences & $1,088,431$ & $1,955,342$ & 0 & $1,134,625$ \\
Probability & $5.41 \times 10^{-6}$ & $8.37 \times 10^{-3}$ & - & $1.32 \times 10^{-2}$ \\
Cut-off & $10^{-16}$ & $10^{-16}$ & $10^{-12}$ & $10^{-12}$ \\
\hline
\end{tabular}

\subsubsection{Phenomenological Model}

A mathematical model has been used to simulate plant dynamics. For the fixed-bed reactor based plant the main features are summarized in the following:

- Compressor (B01): the outlet pressure has been calculated evaluating the pressure drop in the plant; adiabatic compression has been assumed to calculate the outlet temperature and the compression work.

- Filter (F01): in case the filter operates correctly, the outlet flow rate is not modified, while in case the filter is clogged, only a fraction of the gas (assumed to be constant and equal to 50\%) is assumed to pass through the filter, while the rest accumulates upstream the filter increasing the differential pressure. 
- Oxygen input: aiming to maintain constant the oxygen excess in the reactor, the flow rate of oxygen is proportional to the difference between the oxygen concentration in the exhaust gas and the target value.

- Heat recovery device (H01): the heat balance is solved to calculate the outlet temperatures for the cold and hot sides. The global heat exchange coefficient $\left(U, \mathrm{~W} / \mathrm{m}^{2} \cdot \mathrm{K}\right)$ is calculated using the following equation:

$$
\frac{1}{U}=\frac{1}{h_{c}}+\frac{1}{h_{h}}+\frac{s}{k}
$$

where $h\left(\mathrm{~W} / \mathrm{m}^{2} \cdot \mathrm{K}\right)$ is the gas-wall heat transfer coefficient $\left(h_{h}\right.$ for the hot side and $h_{c}$ for the cold side), $k(\mathrm{~W} / \mathrm{m} \cdot \mathrm{K})$ is the wall thermal conductivity, and $s(\mathrm{~m})$ is the wall thickness. The gas-wall heat transfer coefficient is calculated using the following equation:

$$
N u=\frac{h D_{e}}{k_{g}}=0.28 R e^{0.65} \operatorname{Pr}^{0.4}
$$

where $N u$ is the Nusselt number, Re is the Reynolds number, and $\operatorname{Pr}$ is the Prandtl number, $D_{e}(\mathrm{~m})$ is the characteristic length (in our case, the equivalent diameter), $k_{g}(\mathrm{~W} / \mathrm{m} \cdot \mathrm{K})$ is the gas thermal conductivity. The dirtying of the heat exchanger has been simulated considering a reduction of $30 \%$ of the heat exchange coefficient.

- Heater (H02): given the amount of heat provided by the heater, the outlet gas temperature is calculated from the heat balance. In case of failure of the control system of the heater, either the heater gives the highest heating rate $(100 \mathrm{~kW})$, and the gas temperature can be calculated accordingly, or the heater does not give any heat, and the exit temperature is equal to the inlet value.

- Reactor (R01): the set of equations used to calculate the dynamics of the reactor is composed by the energy balance for the gas:

$$
\rho_{g} u_{g} c_{p, g} \varepsilon_{c} \frac{d T_{g}}{d z}-h_{g s} a_{v}\left(T_{s}-T_{g}\right)=0
$$

where $\rho_{g}\left(\mathrm{~kg} / \mathrm{m}^{3}\right)$ is the density of the gas, $u_{g}(\mathrm{~m} / \mathrm{s})$ is the velocity of the gas, $c_{p, g}(\mathrm{~J} / \mathrm{kg} \cdot \mathrm{K})$ is the specific heat of the gas, $\varepsilon_{c}\left(\mathrm{~m}^{3} / \mathrm{m}^{3}\right)$ is the porosity of the bed, $T_{g}(\mathrm{~K})$ is the temperature of the gas, $z$ $(\mathrm{m})$ is the axial coordinate, $h_{g s}\left(\mathrm{~W} / \mathrm{m}^{2} \cdot \mathrm{K}\right)$ is the gas-solid heat transfer coefficient, $a_{v}\left(\mathrm{~m}^{2} / \mathrm{m}^{3}\right)$ is the specific surface of the catalyst, and $T_{S}(\mathrm{~K})$ is the solid temperature, by the energy balance for the solid:

$$
\rho_{s} c_{p, s}\left(1-\varepsilon_{c}\right) \frac{d T_{s}}{d t}=\frac{d^{2} T_{s}}{d z^{2}} k_{s}\left(1-\varepsilon_{c}\right)-h_{g s} a_{v}\left(T_{s}-T_{g}\right)-\left(-\Delta H_{r}\right) \rho_{g} \varepsilon_{c} r_{V O C}
$$

where $\rho_{s}\left(\mathrm{~kg} / \mathrm{m}^{3}\right)$ is the density of the solid, $c_{p, s}$ is the specific heat of the gas $(\mathrm{J} / \mathrm{kg} \cdot \mathrm{K}), t(\mathrm{~s})$ is the time, $k_{s}(\mathrm{~W} / \mathrm{m} \cdot \mathrm{K})$ is the thermal conductivity of the solid, $\Delta H_{r}(\mathrm{~J} / \mathrm{kg})$ is the heat of reaction, and $r_{V O C}\left(\mathrm{~s}^{-1}\right)$ is the specific reaction rate of the VOC) and by the mass balance for the VOC. In this case, the chemical reaction was considered as an instantaneous and complete reaction if the temperature is higher than the reaction temperature. Thus, in presence of an excess of oxygen the following equations are solved:

$$
\left\{\begin{array}{l}
y_{V O C}=0 \\
\frac{d y_{o_{2}}}{d t}=\frac{d y_{o_{2}}}{d z} u_{g}-r_{V O C} \frac{2.5 M_{o_{2}}}{M_{V O C}}
\end{array}\right.
$$

while in case of an excess of VOC the following equations are solved:

$$
\left\{\begin{array}{l}
y_{o_{2}}=0 \\
\frac{d y_{V O C}}{d t}=\frac{d y_{V O C}}{d z} u_{g}-r_{V O C}
\end{array}\right.
$$


where $y_{V O C}(\mathrm{~kg} / \mathrm{kg})$ is the VOC mass fraction, $y_{\mathrm{O} 2}(\mathrm{~kg} / \mathrm{kg})$ is the oxygen mass fraction, $M_{V O C}$ $(\mathrm{kg} / \mathrm{kmol})$ is the VOC molar mass, $M_{\mathrm{O} 2}(\mathrm{~kg} / \mathrm{kmol})$ is the oxygen molar mass. In case the temperature of the solid is lower than the reaction temperature no chemical reaction occurs and, thus, the following equations are solved:

$$
\left\{\begin{array}{l}
\frac{d y_{o_{2}}}{d t}=\frac{d y_{o_{2}}}{d z} u_{g} \\
\frac{d y_{V O C}}{d t}=\frac{d y_{V O C}}{d t} u_{g}
\end{array}\right.
$$

Previous equations require adequate boundary conditions: the temperature and the composition of the gas entering the reactor are equal to the values obtained for the gas leaving the heater H01, and the solid does not exchange heat (by conduction) in correspondence of the two reactor edges.

For the reverse-flow reactor based plant the model of the compressor, of the filter, and of the oxygen input are nor modified. With respect to the reactor, for the catalytic part the equations solved are equal to Equations (1)-(7). For the inert sections the model is composed by the energy balance for the gas phase:

$$
\rho_{g} u_{g} c_{p, g} \varepsilon_{i} \frac{d T_{g}}{d x}-h_{i} a_{v, i}\left(T_{i}-T_{g}\right)=0
$$

where $\rho_{i}\left(\mathrm{~kg} / \mathrm{m}^{3}\right)$ is the inert density, $c_{p, i}(\mathrm{~J} / \mathrm{kg} \cdot \mathrm{K})$ is the inert specific heat, $u_{g}(\mathrm{~m} / \mathrm{s})$ is the velocity of the gas, $\varepsilon_{i}\left(\mathrm{~m}^{3} / \mathrm{m}^{3}\right)$ is the void fraction of the bed of inert, $h_{i}\left(\mathrm{~W} / \mathrm{m}^{2} \cdot \mathrm{K}\right)$ is the gas-inert heat transfer coefficient, $a_{v, i}\left(\mathrm{~m}^{2} / \mathrm{m}^{3}\right)$ is the specific surface area of the inert, and $T_{i}(\mathrm{~K})$ is the temperature of the inert, $T_{g}(\mathrm{~K})$ is the temperature of the gas, $k_{i}(\mathrm{~W} / \mathrm{m} \cdot \mathrm{K})$ is the thermal conductivity of the inert, and by the heat balance for the solid:

$$
\rho_{i} \mathcal{C}_{p, i}\left(1-\varepsilon_{i}\right) \frac{d T_{i}}{d t}=\frac{d^{2} T_{i}}{d x^{2}} k_{i}\left(1-\varepsilon_{i}\right)-h_{i} a_{v, i}\left(T_{i}-T_{g}\right)
$$

and by Equation (7) as no chemical reaction takes place in the inert sections.

The electric heater in the central section, used for control purposes, is modeled using a heat balance for the gas phase:

$$
Q_{h}=\rho_{g} u_{h} c_{p, g} S\left(T_{g, 2}-T_{g, 1}\right)
$$

where $Q_{h}(\mathrm{~W})$ is the heat supplied by the heater, $T_{g, 2}(\mathrm{~K})$ is the gas temperature after the heater, $T_{g, 1}(\mathrm{~K})$ is the gas temperature before the heater e $S\left(\mathrm{~m}^{2}\right)$ is the section of the reactor.

The phenomenological model developed in Matlab according to the above described equations gives results coherent with the literature results.

\section{Consequence Assessment and CBA}

The operational costs and the time losses in case of plant malfunction were used to compare the two plants. The operational costs take into account the recovery of the failed pieces of equipment, the costs related to the plant stops, the cost related to the VOC discharge and the energy consumption. The time lost takes into account the production losses due to plant shut down, for the equipment restoration and the plant start up. Table 2 shows for each major intervention in case of fault or any major consequence, both the costs of the operation and the production time lost, as provided by the plant managers.

Each sequence of events is coupled with a consequence value and the model of its phenomenological behavior. Table 3 shows a sample sequence, where the lack of oxygen in the reactor is due to the lack of oxygen main source, thus bringing to a low temperature in the reactor itself; following the low temperature the sequence includes the failure of the lower temperature protection system (TSL10), but the emergency state is managed thanks to an alarm (TAL10) and the operator intervention. The Table shows also the probability of occurrence of this sequence of events and its consequence. In the case presented in Table 3, the operational cost was evaluate as the sum of the oxygen input system restoration $(2000 €)$, the cost of the emergency shut down $(100,000 €)$ and the 
cost of the energy used in the plant for the year taken into account $(26,500 €)$. The risk value for an unwanted event is the sum of the risks of the sequences of events bringing to the unwanted event itself. The risk value is thus evaluated with Equation (11):

$$
R=\sum C_{i} \cdot P_{i}
$$

where $C_{i}$ is the consequence of the $i$-th sequence of events and $P_{i}$ is its probability.

Table 2. Summary of cost and time loss.

\begin{tabular}{ccc}
\hline Intervention & Estimated Costs & Estimated Time \\
\hline Restore filter & $200 €$ & $3 \mathrm{~h}$ \\
Restore system of input of oxygen & $2000 €$ & $2 \mathrm{~h}$ \\
Restore heat recovery & $20,000 €$ & 5 days \\
Restore heater & $10,000 €$ & 1 day \\
Restore blower & $2000 €$ & 1 day \\
Restore valve of reactor & $10,000 €$ & 2 days \\
Restore heat control inside of reactor & $2000 €$ & 3 days \\
Replace catalyst in traditional plant & $200 € / \mathrm{dm}^{3}$ & 7 days \\
Replace catalyst in intensified plant & $17,500 €$ & 7 days \\
Plant stop & $100,000 €$ & 1 day \\
Cost no abatement of VOCs & $60,000 €$ & - \\
Cost of electric power & $0.16 € / \mathrm{kWh}$ & - \\
\hline
\end{tabular}

Table 3. Example of an events' sequence.

\begin{tabular}{|c|c|c|c|c|c|}
\hline \multicolumn{3}{|c|}{ Sequences Number 10119} & \multicolumn{3}{|c|}{ Probability $2.43 \times 10^{-9}$} \\
\hline \multicolumn{2}{|c|}{ Out Service } & $26 \mathrm{~h} /$ Year & \multicolumn{2}{|l|}{ Risk (out of Service) } & \multirow{2}{*}{$\begin{array}{c}6.31 \times 10^{-8} \mathrm{~h} / \text { Year } \\
0.0003 € / \text { Year }\end{array}$} \\
\hline \multicolumn{2}{|c|}{ Operational Cost } & \multirow{2}{*}{$\begin{array}{c}128,500 € / \text { Year } \\
\text { Cumulative Probability }\end{array}$} & \multicolumn{2}{|l|}{ Risk (Operational Cost) } & \\
\hline Level & Probability & & Description & $\begin{array}{c}\text { Out Service } \\
\text { (h/Year) }\end{array}$ & Cost (€/Year) \\
\hline 1 & $1-1.00 \times 10^{-3}$ & 0.999 & Input temperature? OK & - & - \\
\hline 3 & $1-1.00 \times 10^{-3}$ & 0.998 & Input VOCs concentration? OK & - & - \\
\hline 5 & $1-1.00 \times 10^{-3}$ & 0.997 & Input Flow? OK & - & - \\
\hline 50 & $1-8.40 \times 10^{-2}$ & 0.913 & Blower B01? OK & - & - \\
\hline 52 & $1-9.50 \times 10^{-2}$ & 0.827 & FE01? OK & - & - \\
\hline 53 & $1-2.52 \times 10^{-1}$ & 0.618 & FIC01? OK & - & - \\
\hline 54 & $1-2.31 \times 10^{-1}$ & 0.475 & FCV01? OK & - & - \\
\hline 55 & - & 0.475 & Flow after the blower? OK & - & - \\
\hline 100 & $1-9.00 \times 10^{-1}$ & 0.0475 & Filter F01? OK & - & - \\
\hline 150 & $1-6.20 \times 10^{-2}$ & 0.0446 & $\mathrm{AE02}(\mathrm{O} 2)$ ? OK & - & - \\
\hline 151 & $1-9.50 \times 10^{-2}$ & 0.040357 & AT02? OK & - & - \\
\hline 152 & $1-2.52 \times 10^{-1}$ & 0.030187 & AICA02? OK & - & - \\
\hline 153 & $1-1.81 \times 10^{-1}$ & 0.024723 & FE02? OK & - & - \\
\hline 154 & $1-9.50 \times 10^{-2}$ & 0.022375 & FT02? OK & - & - \\
\hline 155 & $1-2.52 \times 10^{-1}$ & 0.016736 & FIC02? OK & - & - \\
\hline 156 & $1-2.31 \times 10^{-1}$ & 0.01287 & FV02? OK & - & - \\
\hline 157 & 0.001 & $1.29 \times 10^{-5}$ & $\mathrm{O} 2$ is Available? NO & 2 & 2.000 \\
\hline 160 & - & $1.29 \times 10^{-5}$ & The O2 concentration? Low & - & - \\
\hline 230 & $1-7.00 \times 10^{-3}$ & $1.28 \times 10^{-5}$ & V01? OK & - & - \\
\hline 232 & $1-7.00 \times 10^{-3}$ & $1.27 \times 10^{-5}$ & V02? OK & - & - \\
\hline 234 & $1-7.00 \times 10^{-3}$ & $1.26 \times 10^{-5}$ & V03? OK & - & - \\
\hline 236 & $1-7.00 \times 10^{-3}$ & $1.25 \times 10^{-5}$ & V04? OK & - & - \\
\hline 245 & $\begin{array}{c}-100 \\
-\end{array}$ & $1.25 \times 10^{-5}$ & Flow from V01 to V04? Correct & - & - \\
\hline 255 & - & $1.25 \times 10^{-5}$ & Flow from V02 to V03? Correct & - & - \\
\hline 276 & - & $1.25 \times 10^{-5}$ & Temperature inside reactor? Low & - & - \\
\hline 500 & $1-8.40 \times 10^{-2}$ & $1.15 \times 10^{-5}$ & TE10? OK & - & - \\
\hline 502 & $1-2.52 \times 10^{-1}$ & $8.57 \times 10^{-6}$ & TIC10? OK & - & - \\
\hline 521 & 0.0003 & $2.57 \times 10^{-9}$ & TSL10? Fault & - & - \\
\hline 528 & - & $2.57 \times 10^{-9}$ & The system TSL10 is effectiveness? NO & - & - \\
\hline 504 & $1-2.50 \times 10^{2}$ & $2.51 \times 10^{-9}$ & TAL10? OK & - & - \\
\hline 505 & $1-3.00 \times 10^{-2}$ & $2.43 \times 10^{-9}$ & Operator occur on TAL10? YES & - & - \\
\hline 506 & $\begin{array}{c}-5.00 \\
-\end{array}$ & $2.43 \times 10^{-9}$ & TLA10 is effectiveness? YES-Emergency & - & - \\
\hline 602 & - & $2.43 \times 10^{-9}$ & Plant status? Emergency & 24 & 100.000 \\
\hline- & - & - & Power & & 26.500 \\
\hline
\end{tabular}




\section{Results and Discussion}

In this section, the results of the logical-probabilistic and phenomenological modelling are discussed.

Figure 4 shows the probability of occurrence of the sequences bringing to the discharge with an excess of VOCs, also represented in Figure 5 in terms of risk; Figure 6 shows the 100 more relevant sequences of events ((a) for the out of service risk and (b) for the operational cost risk).

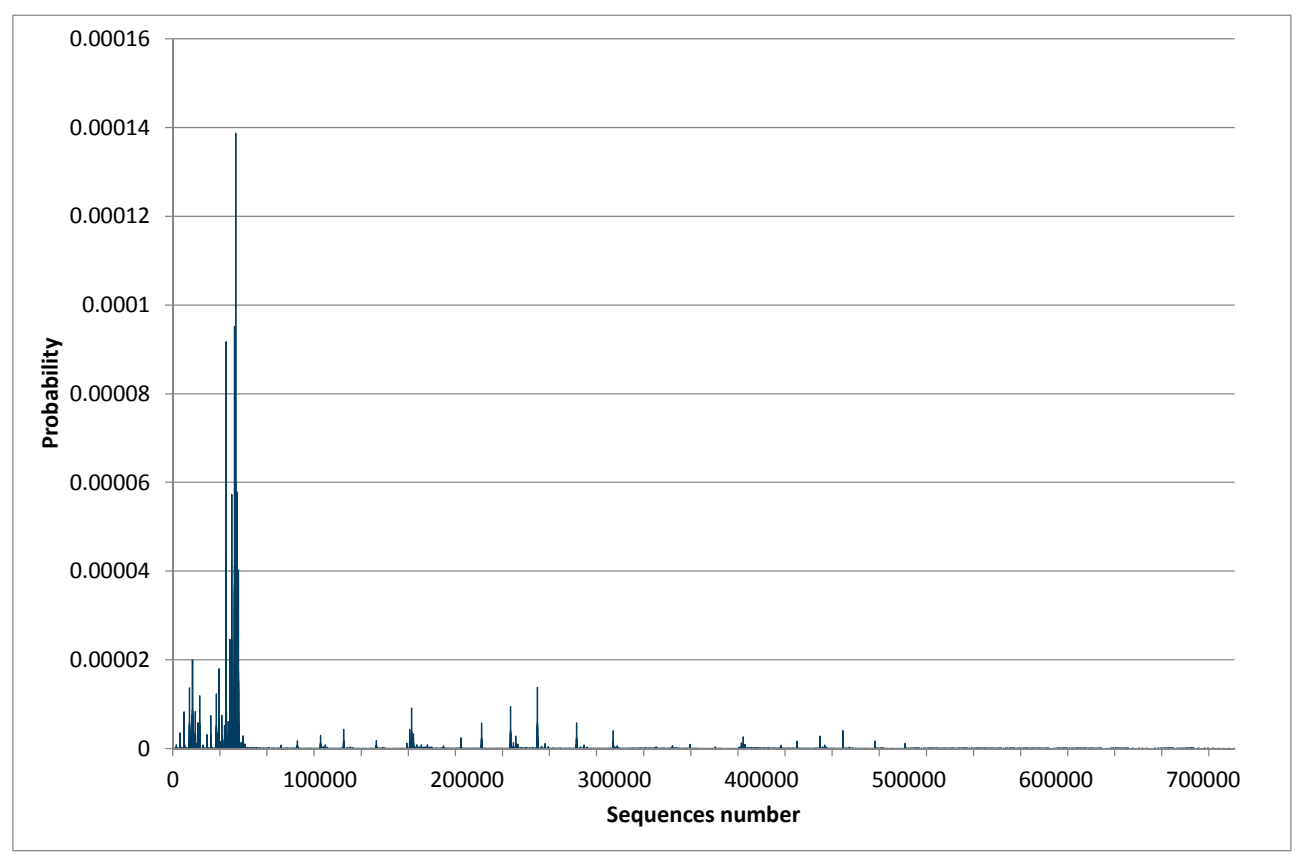

Figure 4. The probability of the sequences of events contain the high concentration of VOCs in the output for the fixed-bed based plant.

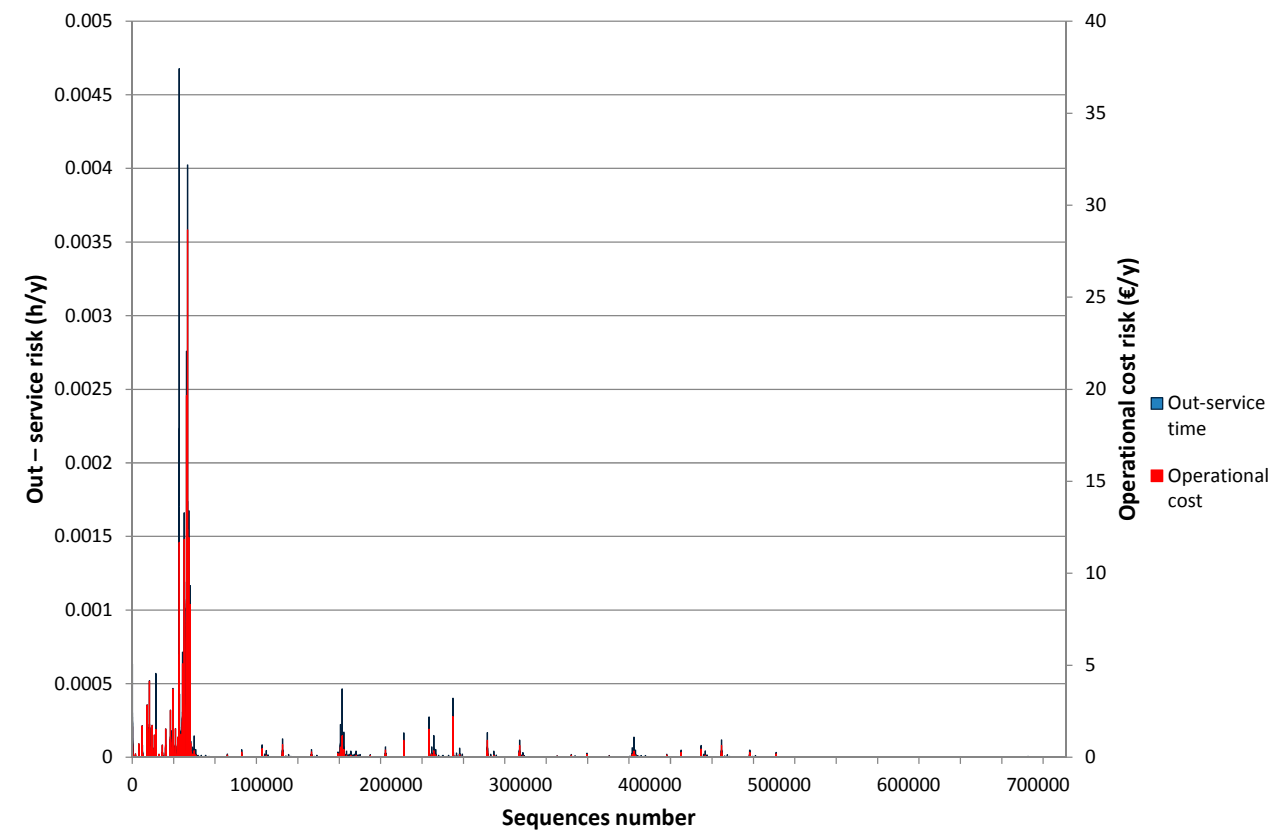

Figure 5. The risk of the sequences of events contain the high concentration of VOCs in the output for the fixed-bed based plant. 
Both Figures highlight how a small number of sequences mainly contributes to the global probability or risk. Those major contributors are the sequences where the oxygen input fails or the heater fails, without the intervention of the alarm and/or of the protective systems. It can be observed that the operational cost risk has the same trend of the probability, while for the out-of-service risk the relevance of the sequences is different with respect to the probabilities. In fact, the main contributors are those pertaining the failure of the heater, while those involving the oxygen feed failure are less relevant.

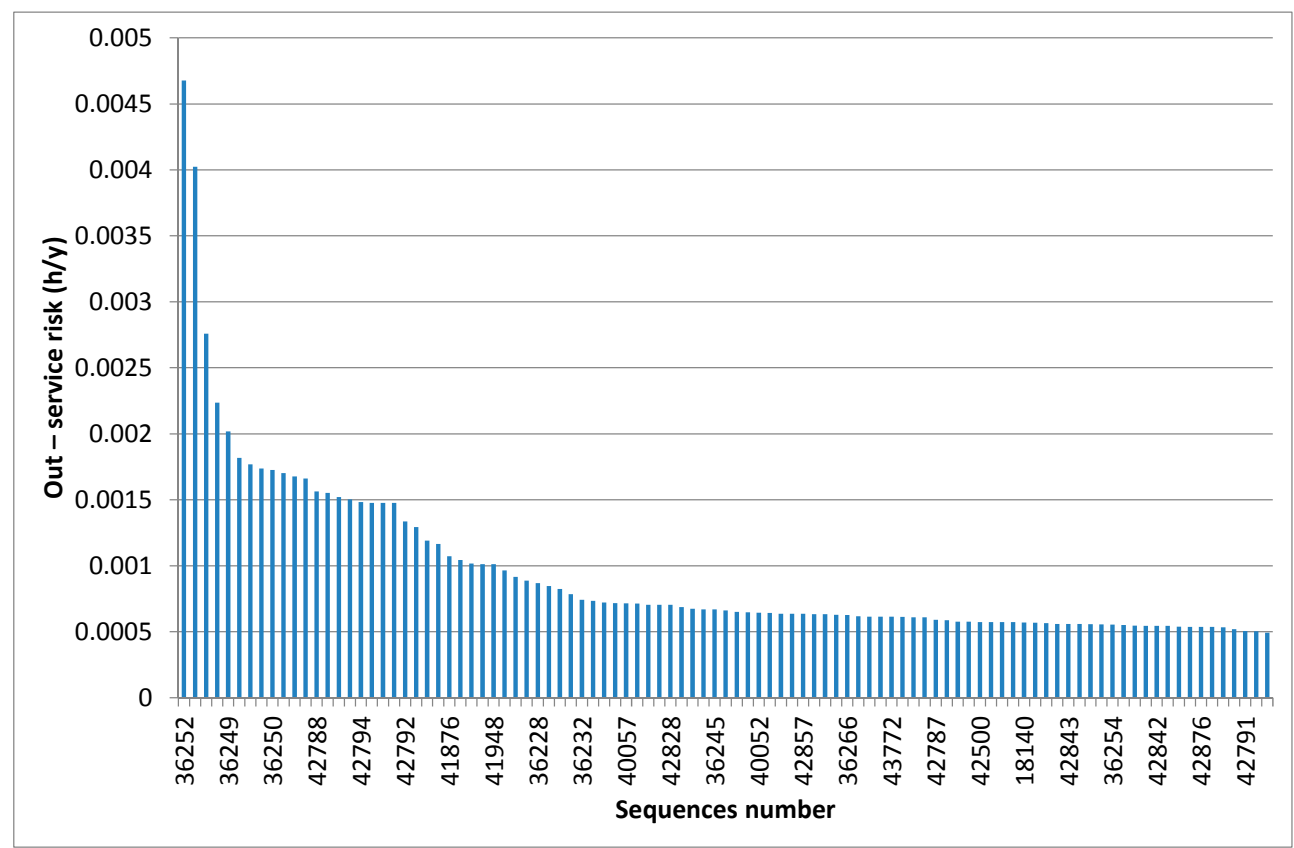

(a)

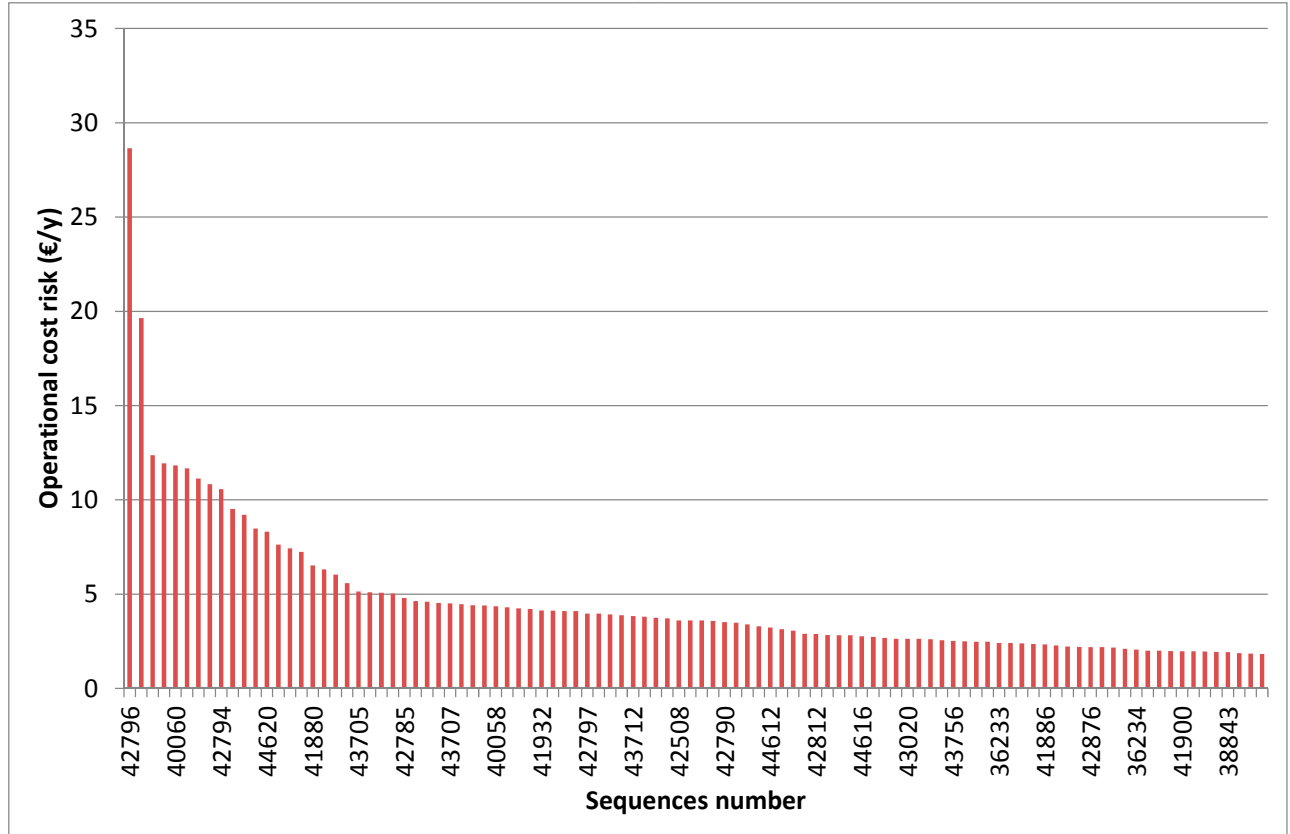

(b)

Figure 6. Details of the results bringing to high concentrations of VOCs in the output stream for the fixed bed based plant (a) The 100 sequences with the higher value of out-service time risk; (b) The 100 sequences with the and higher value of risk of operational cost. 
Figure 7 shows the distribution of the probabilities bringing to the discharge with an excess of VOCs, while Figure 8 represents the risk associated to the same sequences risk; Figure 9 shows the 100 more relevant sequences of events ((a) for the out-service risk and (b) the operational cost risk). Also for the reverse-flow based plant a small number of sequences brings the higher contribution to the global value of probability or risk. These sequences include the fault of the oxygen input system and differ for the system's component failing. The probability and the risk values show the same trend.

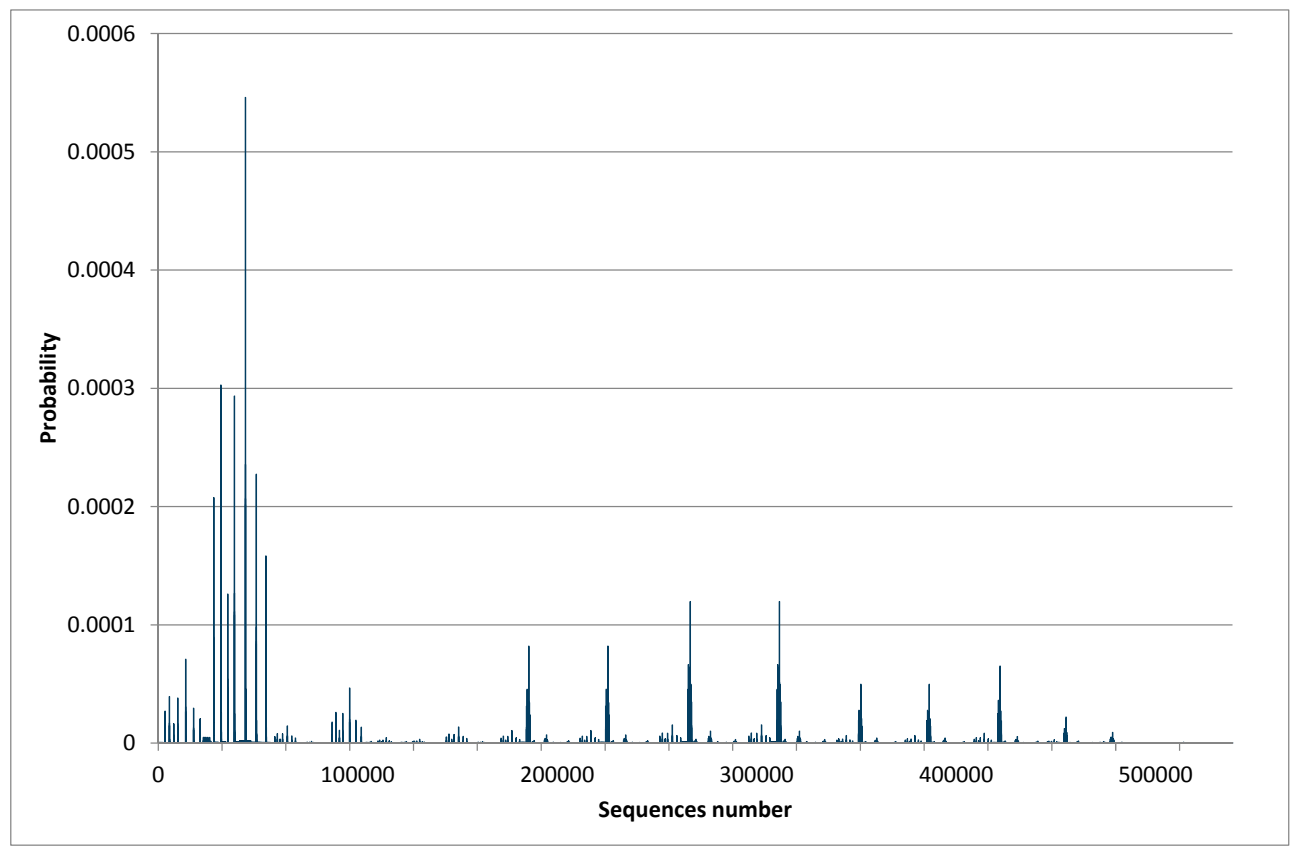

Figure 7. The probability of the sequences of events contain the high concentration of VOCs in the output for the reverse-flow based plant.

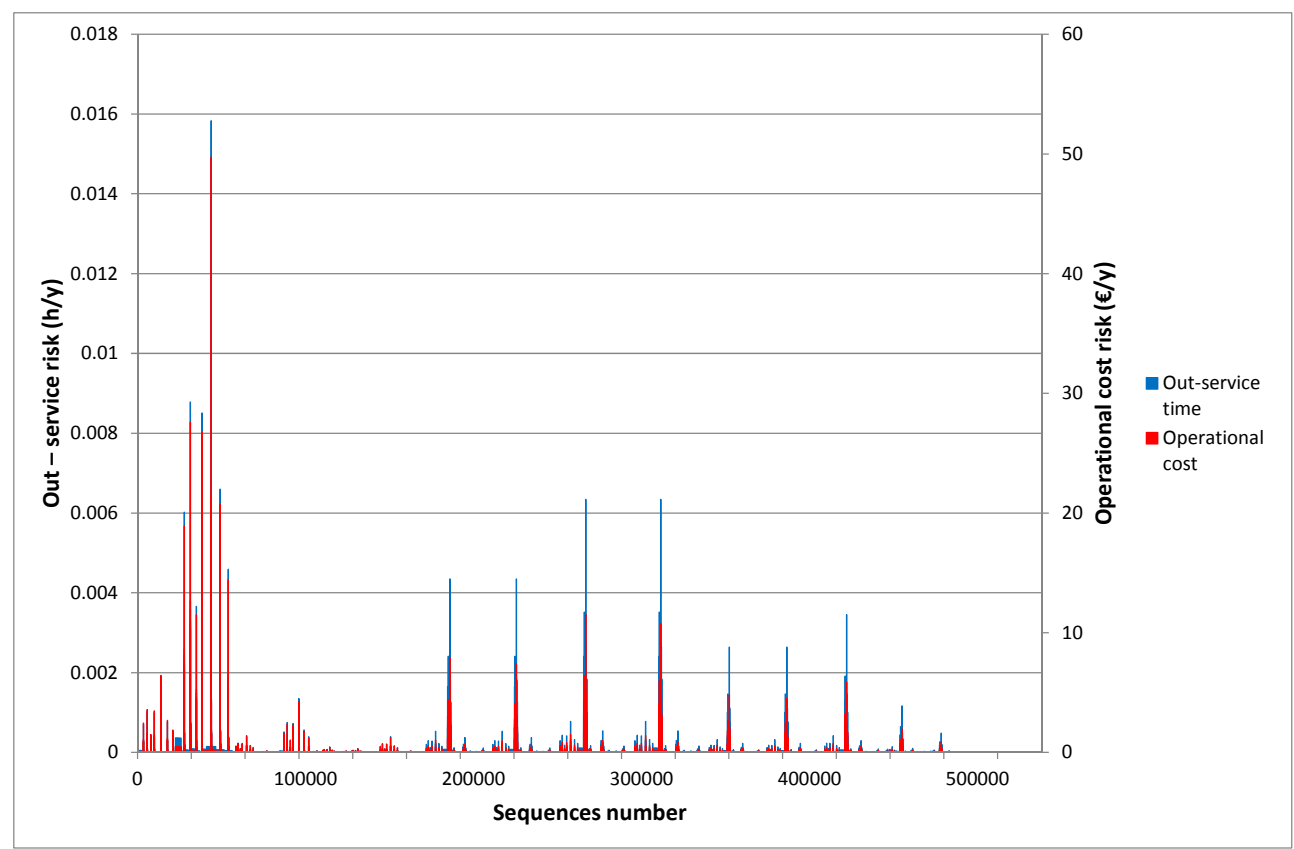

Figure 8. The risk of the sequences of events contain the high concentration of VOCs in the output for the reverse flow plant. 


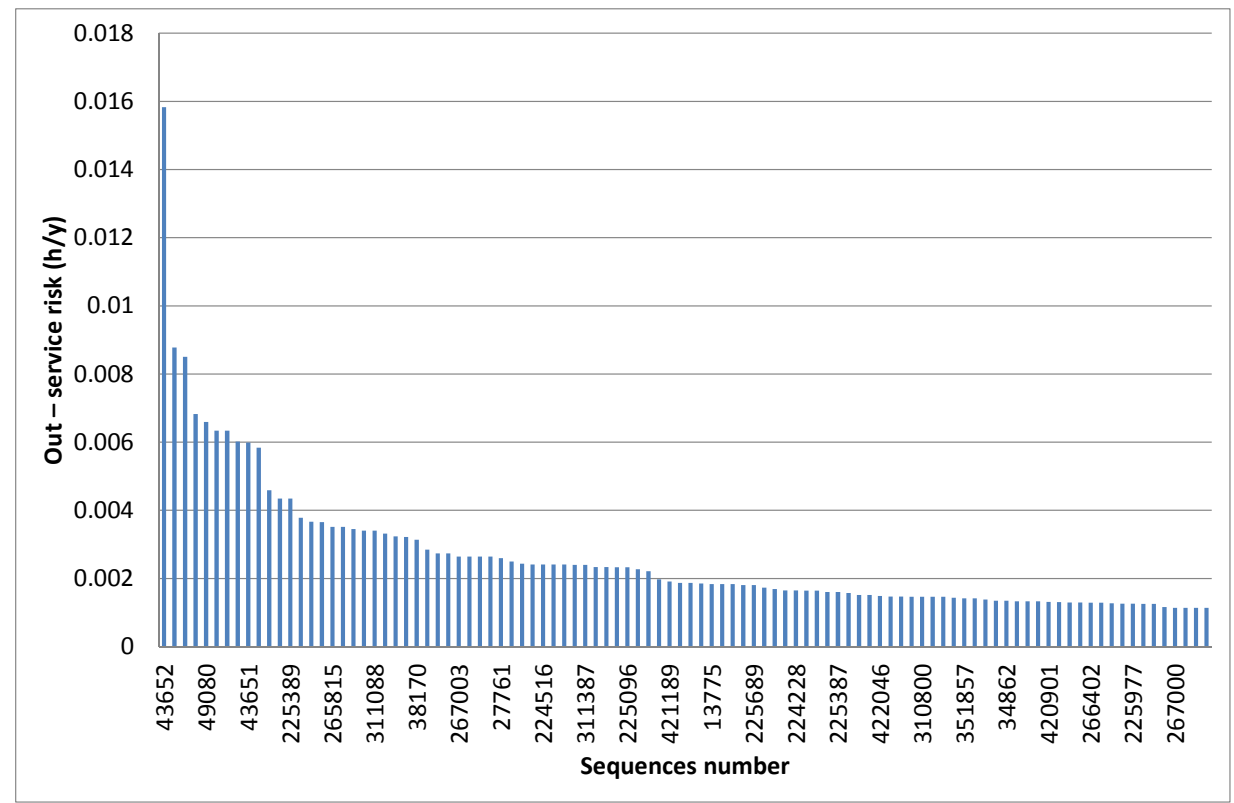

(a)

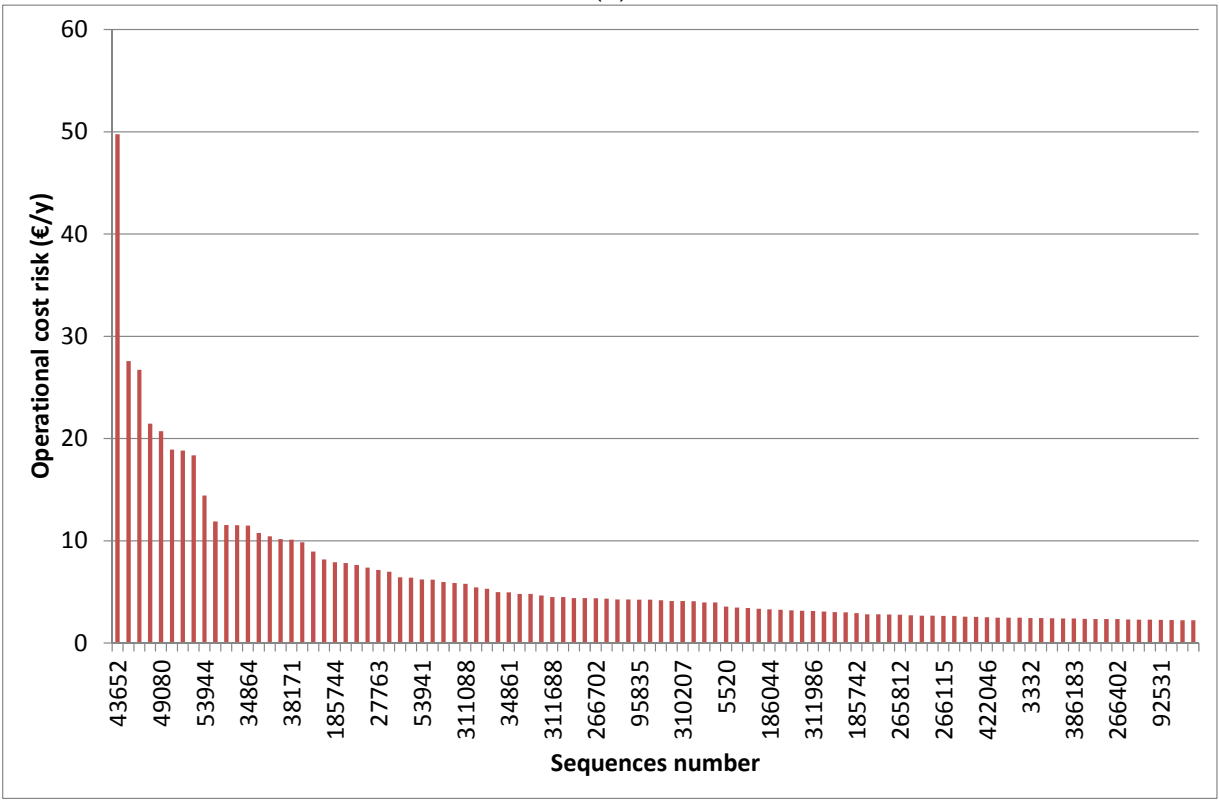

(b)

Figure 9. Details of the results bringing to high concentrations of VOCs in the output stream for the revers flow plant (a) The 100 sequences with the higher value of out-service time risk; (b) The 100 sequences with the and higher value of risk of operational cost.

From the comparison between the risk figures it is possible to conclude that the reverse-flow based plant is less risky than the fixed-bed based plant from the operational costs point of view, mainly thanks to the lower energy consumption. In terms of service outage, the reverse-flow based plant appears to be riskier than the fixed-bed based plant, because of its higher complexity, with a higher time needed for restoration after a failure.

Analyzing the sintering of the catalyst, that represents a critical event for the plant operations, the fixed-bed based plant shows a $5.41 \times 10^{-6}$ probability of occurrence, while the reverse-flow based plant does not have sequences of events bringing to the sintering of the catalyst with a probability of occurrence higher than the cut off value $\left(10^{-12}\right)$. In a precautionary way, all the sequences constituting the residual probability were assimilated to the catalyst sintering probability in the reverse-flow 
based plant, although this is an overestimation of the probability itself. In Figure 10 the probability distribution of the sequences of events for the catalyst sinterization in the fixed-bed based plant is shown. In Figure 11 the risk distribution is shown. In these two graphs the more relevant sequences include the filter obstruction combined to the fault of the heater control system. Figure 12 shows the 100 more relevant sequences of events ((a) for the out-service risk and (b) for the operational cost).

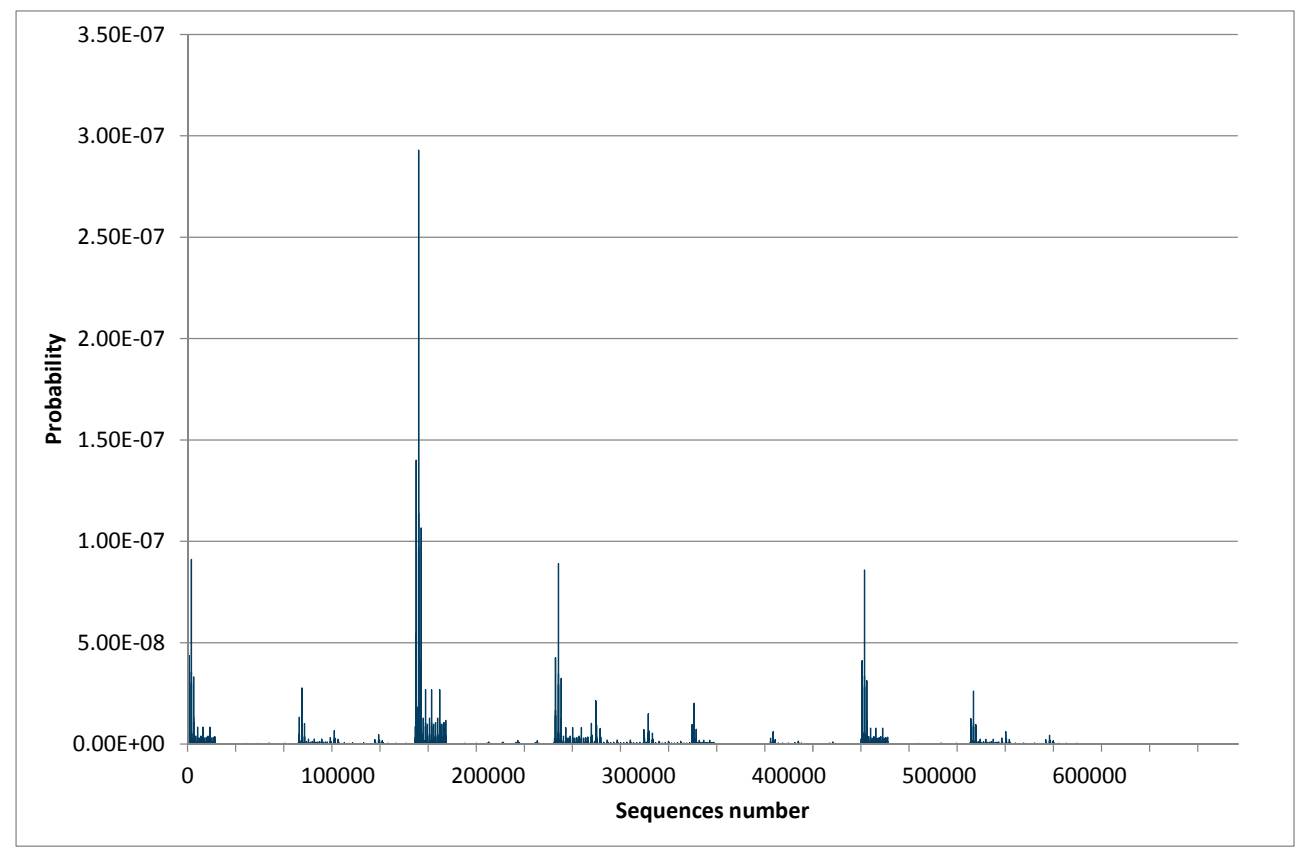

Figure 10. The probability of the sequences of events contain the catalyst sinterization for the fixed-bed based plant.

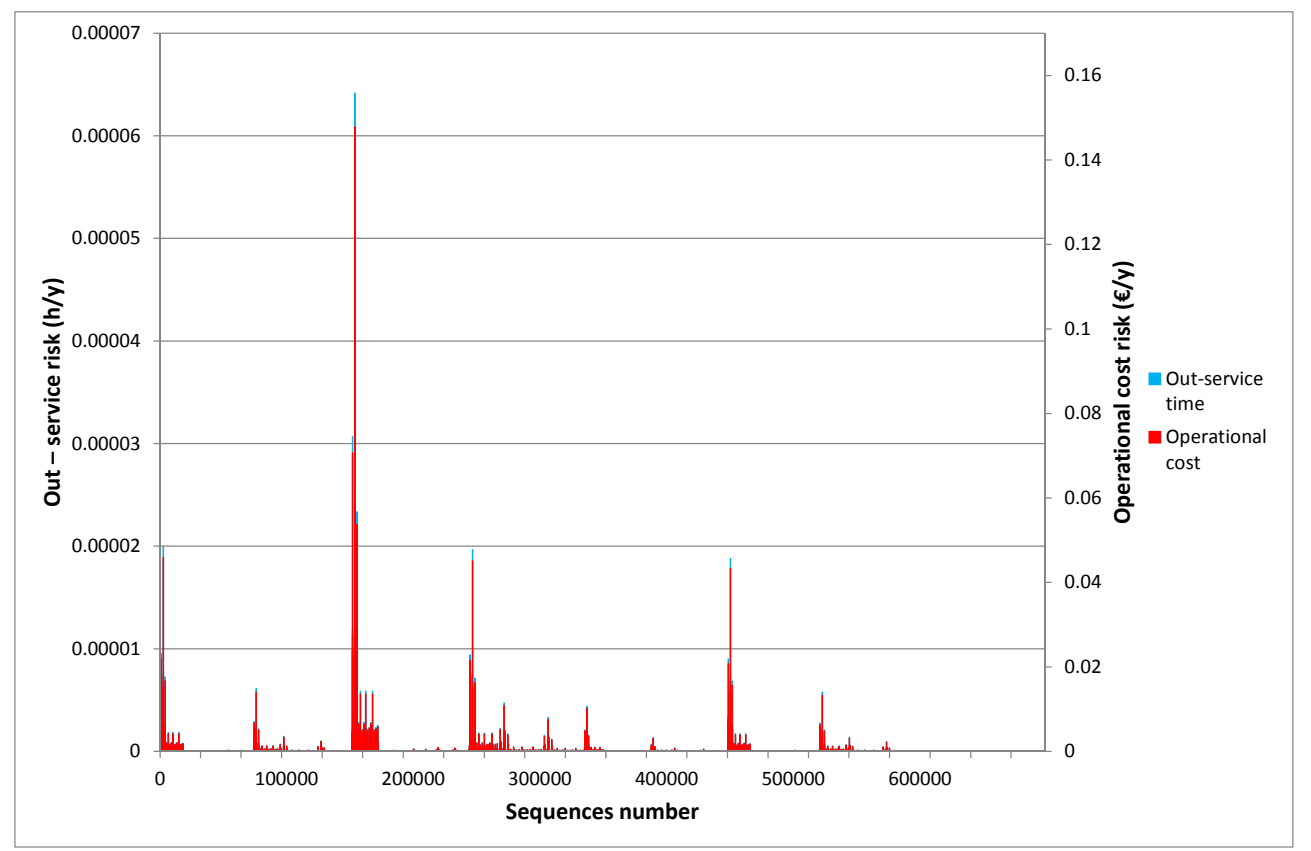

Figure 11. The risk of the sequences of events contain the catalyst sinterization for the fixed-bed based plant. 


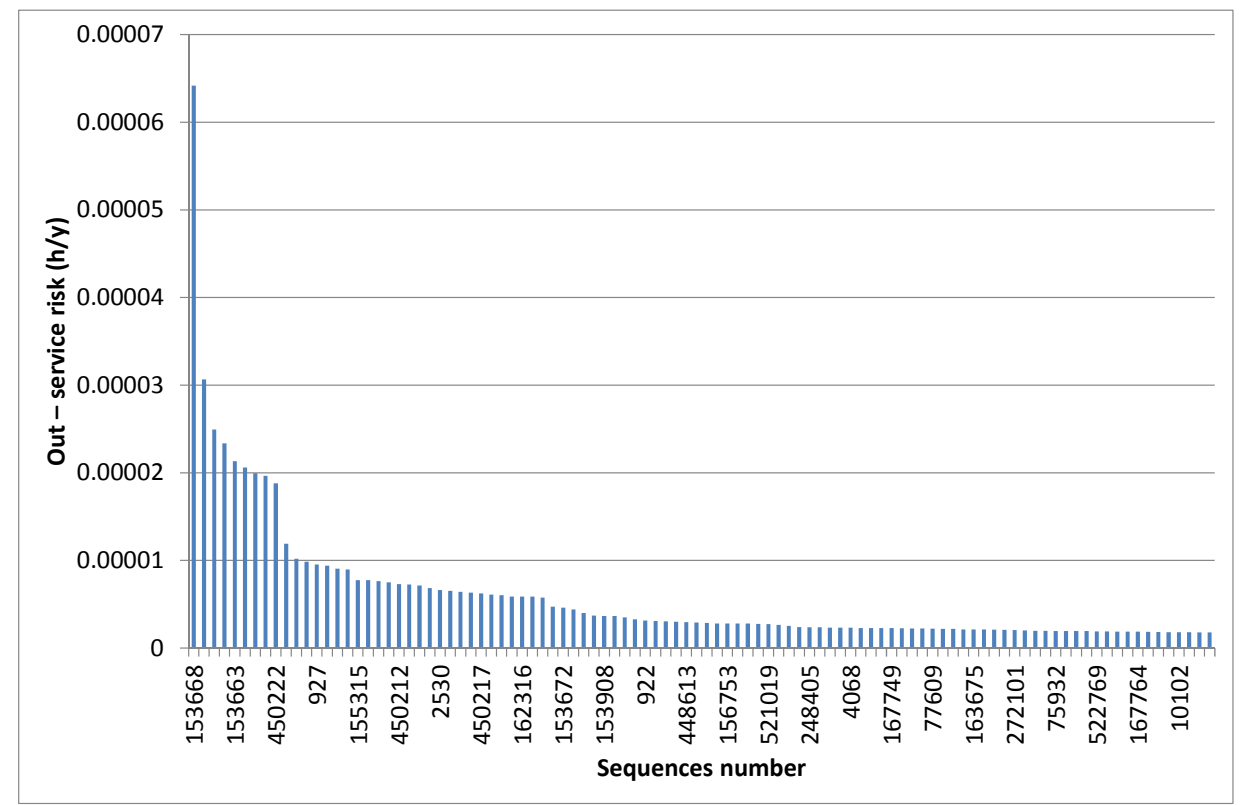

(a)

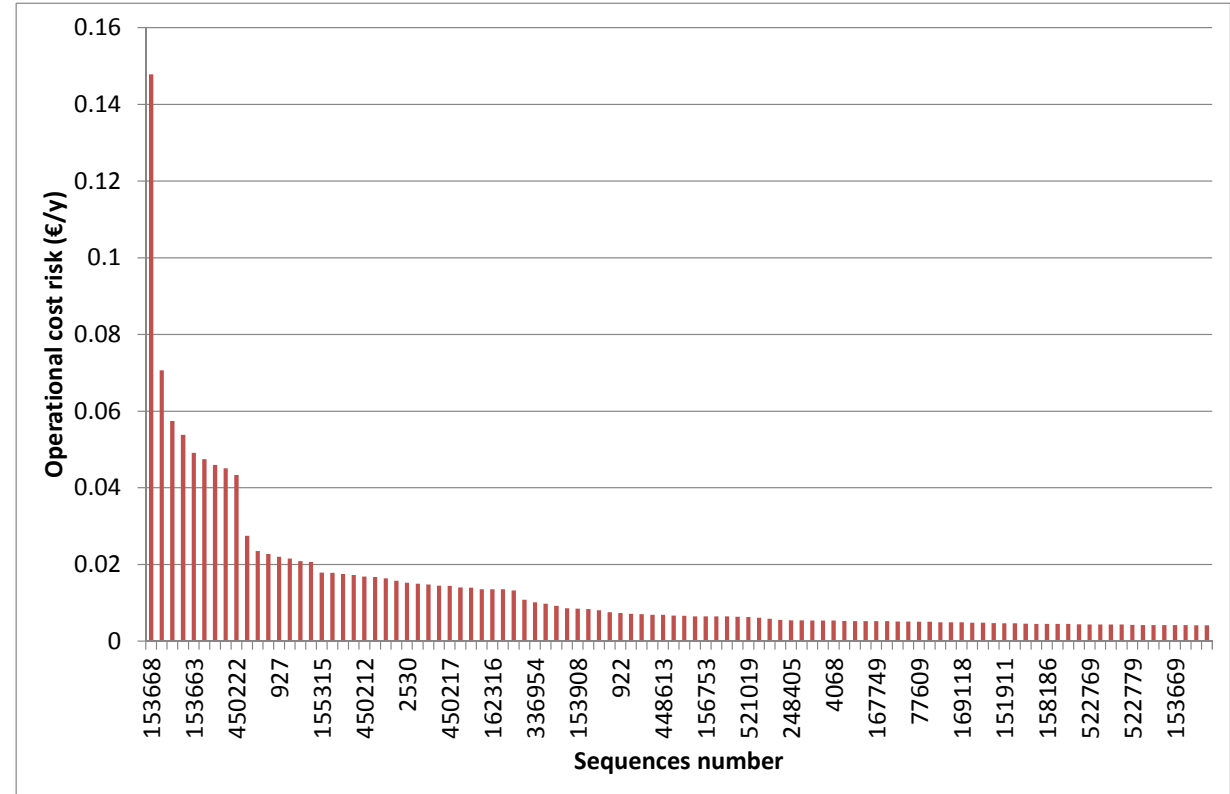

(b)

Figure 12. Details of the results bringing to the catalyst sinterization for the fixed bed based plant (a) The 100 sequences with the higher value of out-service time risk; (b) The 100 sequences with the and higher value of risk of operational cost.

Table 4 shows the summary of the results used for the risk based decision-making. It also shows the mean values of the annual operation cost and the time losses evaluate for the sequences taken into account. The discharge with excess of VOCs causes an unwanted shut down of the plant, with possible process problems on the subsequent systems. The fixed bed plant appears to be more reliable than the reverse flow plant $\left(8.37 \times 10^{-3}\right.$ vs. $1.32 \times 10^{-2}$ of probability $)$.

The risk of discharge with excess of VOCs for the fixed bed plant corresponds to $1400 €$ /year and $0.35 \mathrm{~h}$ /year in terms of the time losses. For the reverse-flow based plant, instead, the risk figures are $1200 € /$ year and $0.56 \mathrm{~h} /$ year. 
Table 4. Fixed bed plant and reverse flow plant results.

\begin{tabular}{ccccc}
\hline \multirow{2}{*}{ Indicator } & \multicolumn{2}{c}{ Fixed Bed Plant } & \multicolumn{2}{c}{ Reverse Flow Plant } \\
\cline { 2 - 5 } & $\begin{array}{c}\text { Sintering of } \\
\text { Catalyst }\end{array}$ & $\begin{array}{c}\text { Discharge with } \\
\text { Excess of VOCs }\end{array}$ & $\begin{array}{c}\text { Sintering of } \\
\text { Catalyst }\end{array}$ & $\begin{array}{c}\text { Discharge with } \\
\text { Excess of VOCs }\end{array}$ \\
\hline Probability & $5.41 \times 10^{-6}$ & $8.37 \times 10^{-3}$ & $2.9 \times 10^{-61}$ & $1.32 \times 10^{-2}$ \\
Annual operational costs, $€ /$ year & 500,000 & 171,000 & 144,000 & 92,000 \\
Risk, $€ /$ year & 2.7 & 1400 & 0.4 & 1200 \\
Time losses, h/year & 219 & 42 & 192 & 43 \\
Risk, h/year & $1.2 \times 10^{-3}$ & 0.35 & $5.6 \times 10^{-4}$ & 0.56 \\
Number of sequences & 698,688 & 721,461 & 0 & 538,590 \\
\hline
\end{tabular}

${ }^{1}$ This probability value is the residual probability value used in conservative way for probability of the event here described for the plant intensified.

\section{Conclusions}

In the case study for the selection of competing technologies for the VOCs treatment, from the analysis of the results it is possible to conclude that, depending on the benefits the stakeholder is interested in, the following conclusions can be drawn.

Considering the time losses following a failure, the two plant alternatives appear to be comparable in terms both of consequences and of risk of discharge with an execs of VOCs. For both plants the more critical system appear to be the input of oxygen, on which the inspections and maintenance activities should be concentrated.

When the benefits related to the minimization of the operational costs are taken into account, instead, the intensified plant (reverse-flow reactor) is the best option, since it can run with a less expensive catalyst and it requires less energy.

Thus, given the above considerations, the reverse flow reactors appear to be the most effective technology to treat lean-VOC streams.

The different risk figures allow the management to have a global view of the plant foreseeable behavior and to take better and more informed decisions.

The subsequent decision depends on the final aim of the plant managers, that have in any case available the full picture of the behavior of the plant alternatives.

The Integrated Dynamic Decisional Analysis appears to be an effective way to help the management to perform a risk based decision between different technological solution The IDDA analysis allow analyzing in a systematic way the plant behavior in case of normal condition and in case of process deviation and/or equipment failure. It also allows to evaluate the occurrence probability of the unwanted outcomes, but also their risk value in a cost-benefit shape.

Author Contributions: The three authors jointly conceived the paper based on the case study of industrial interest. Davide Fissore developed the phenomenological model, implemented by Gabriele Baldissone. Micaela Demichela and Gabriele Baldissone developed and implemented the logical and probabilistic model. All the authors jointly analysed the results and wrote the paper.

Conflicts of Interest: The authors declare no conflict of interest.

\section{References}

1. Kolaczkowski, S. Treatment of Volatile Organic Carbon. Emissions from stationary sources: Catalytic oxidation of the gaseous phase. In Structured Catalysts and Reactors, 2nd ed.; CRC Press: Boca Raton, FL, USA, 2006.

2. Barresi, A.A.; Baldi, G.; Fissore, D. Forced unsteady-state reactors as efficient devices for integrated processes: Case histories and new perspectives. Ind. Eng. Chem. Res. 2007, 46, 8693-8700. [CrossRef]

3. Cottrell, F.G. Purifying Gases and Apparatus Therefore. U.S. Patent 2,171,733, 21 June 1938.

4. Eigenberger, G.; Nieken, U. Catalytic combustion with periodical flow reversal. Chem. Eng. Sci. 1988, 43, 2109-21198. [CrossRef]

5. Nieken, U.; Eigenberger, G. Fixed-bed reactors with periodic flow reversal: Experimental results for catalytic combustion. Catal. Today 1994, 38, 335-350. [CrossRef] 
6. Matros, Y.S.; Bunimovich, G.A. Reverse-flow operation in catalytic reactors. Catal. Rev. 1996, 38, 1-68. [CrossRef]

7. Van de Beld, L.; Westerterp, K.R. Air purification in a reverse-flow reactor: Model simulations vs. experiments. AIChE J. 1996, 42, 1139-1148. [CrossRef]

8. Zufle, H.; Turek, T. Catalytic combustion in a reactor with periodic flow reversal: 1. Experimental results. Chem. Eng. Process. Process Intensif. 1997, 36, 327-339. [CrossRef]

9. Fissore, D.; Barresi, A.A.; Baldi, G.; Hevia, M.A.G.; Ordònez, S.; Dìez, F.V. Design and Testing of Small-Scale Unsteady-State Afterburners and Reactors. AIChE J. 2005, 51, 1654-1664. [CrossRef]

10. Cittadini, M.; Vanni, M.; Barresi, A.A.; Baldi, G. Reverse-Flow catalytic burners: Response to periodical variations in the feed. Chem. Eng. Sci. 2001, 56, 1443-1449. [CrossRef]

11. Chen, G.; Chi, Y.; Yan, J.; Ni, M. Effect of periodic variation of the inlet concentration on the performance of reverse flow reactors. Ind. Eng. Chem. Res. 2011, 50, 5448-5458. [CrossRef]

12. Marín, P.; Ordóñez, S.; Díez, F.V. Monoliths as suitable catalysts for reverse-flow combustors: Modeling and experimental validation. AIChE J. 2011, 56, 3162-3173. [CrossRef]

13. Kolios, G.; Frauhammer, J.; Eigenberger, G. Autothermal fixed-bed reactor concepts. Chem. Eng. Sci. 2000, 55, 5945-5967. [CrossRef]

14. Luzi, C.D.; Martínez, O.M.; Barreto, G.F. Autothermal reverse-flow reactors: Design and comparison of valve-operated and rotary systems. Chem. Eng. Sci. 2016, 148, 170-181. [CrossRef]

15. Demichela, M.; Piccinini, N. Integrated dynamic decision analysis: A method for PSA in dynamic process system. In Proceedings of the CISAP 3, Rome, Italy, 11-14 May 2008; AIDIC: Milano, Italy, 2008.

16. Demichela, M.; Camuncoli, G. Risk based decision making. Discussion on two methodological milestones. J. Loss Prev. Process Ind. 2014, 28, 101-108. [CrossRef]

17. Leva, M.C.; Pirani, R.; Demichela, M.; Clancy, P. Human factors issues and the risk of high voltage equipment: Are standards sufficient to ensure safety by design? Chem. Eng. Trans. 2012, 26, 273-278.

18. Demichela, M.; Pirani, R.; Leva, M.C. Human factor analysis embedded in risk assessment of industrial machines: Effects on the safety integrity level. Int. J. Perform. Eng. 2014, 10, 487-496.

19. Saarikoski, H.; Mustajoki, J.; Barton, D.N.; Geneletti, D.; Langemeyer, J.; Gomez-Baggethun, E.; Marttunen, M.; Antunes, P.; Keune, H.; Santos, R. Multi-Criteria Decision Analysis and Cost-Benefit Analysis: Comparing alternative frameworks for integrated valuation of ecosystem services. Ecosyst. Serv. 2016, 22, 238-249. [CrossRef]

20. Dixon, J.A.; Hufschmidt, M. Economic Valuation Techniques for the Environment. A Case Study Workbook; Johns Hopkins University Press: Baltimore, MA, USA, 1986.

21. Boardman, A.; Greenberg, D.; Vining, A.; Weimer, D. Cost-Benefit Analysis. Concepts and Practice; Pearson Prentice Hall: Upper Saddle River, NJ, USA, 2011.

22. Ferreira, S.; Cabral, M.; da Cruz, N.F.; Simões, P.; Marques, R.C. The costs and benefits of packaging waste management systems in Europe: The perspective of local authorities. J. Environ. Plan. Manag. 2017, 60, 773-791. [CrossRef]

23. Nichol, KL. Cost-Benefit Analysis of a Strategy to Vaccinate Healthy Working Adults against Influenza. Arch. Intern. Med. 2001, 161, 749-759. [CrossRef] [PubMed]

24. Diakoulaki, D.; Karangelis, F. Multi-criteria decision analysis and cost-benefit analysis of alternative scenarios for the power generation sector in Greece. Renew. Sustain. Energy Rev. 2007, 11, 716-727. [CrossRef]

25. Clementel, S.; Galvagni, R. The use of the event tree in the design of nuclear power plants. Environ. Int. 1984, 10, 377-382. [CrossRef]

26. Galvagni, R.; Clementel, S. Risk analysis as an instrument of design. In Safety Design Criteria for Industrial Plants; Cumo, M., Naviglio, A., Eds.; CRC Press: Boca Raton, FL, USA, 1989; Volume 1.

27. Turja, A.; Demichela, M. Risk based design of allyl chloride production plant. Chem. Eng. Trans. 2011, 24, 1087-1092.

28. Gerbec, M.; Baldissone, G.; Demichela, M. Design of procedures for rare, new or complex processes: Part 2-Comparative risk assessment and CEA of the case study. Saf. Sci. in press. [CrossRef]

29. Mannan, S. Lee's Loss Prevention in the Process Industries; Elsevier: Oxford, UK, 2005.

(C) 2017 by the authors. Licensee MDPI, Basel, Switzerland. This article is an open access article distributed under the terms and conditions of the Creative Commons Attribution (CC BY) license (http:/ / creativecommons.org/licenses/by/4.0/). 